\title{
Comparison of different starting gonadotropin doses (50, 75 and 100 IU daily) for ovulation induction combined with intrauterine insemination
}

\author{
Robert Streda $\cdot$ Tonko Mardesic • Vladimir Sobotka • \\ Dana Koryntova $\cdot$ Lucie Hybnerova $\cdot$ \\ Martin Jindra
}

Received: 1 February 2012/ Accepted: 4 June 2012/Published online: 27 June 2012

(C) The Author(s) 2012. This article is published with open access at Springerlink.com

\begin{abstract}
Purpose To prevent multiple pregnancies the goal of ovulation induction by gonadotropins is to achieve only mono-follicular development. The most important issue is therefore to determine the starting dose. The aim of this study is to compare three different starting doses of follitropin beta to assess the lowest effective dose.

Methods We evaluated 92 cycles with ovarian stimulation for patients with unexplained infertility, anovulatory disorder or mild male factor. We prospectively divided patients into 50, 75 and 100 IU groups based on patients' response to clomiphene citrate treatment.

Results We performed 87 intrauterine inseminations (95\% of cycles with ovulation induction). Five cycles were cancelled. We achieved 15 pregnancies; total pregnancy rate was $18 \%$. Pregnancy rate was 22,10 and $28 \%$ in 50, 75 and 100 IU follitropin beta groups. The average number of follicles was $2.0 \pm 0.8,2.2 \pm 1.1$ and $2.5 \pm 1.8$ (ns), total dose of gonadotropins (IU) $483 \pm 192$, $600 \pm 151$ and $830 \pm 268(p<0.001)$, respectively. We
\end{abstract}

R. Streda $(\bowtie) \cdot$ T. Mardesic · V. Sobotka

Sanatorium Pronatal, Na Dlouhé Mezi 4/12, Prague,

Czech Republic

e-mail: rstreda@seznam.cz

R. Streda - T. Mardesic - V. Sobotka - D. Koryntova ·

L. Hybnerova $\cdot$ M. Jindra

Pronatal Plus, Prague, Czech Republic

R. Streda

Department of Obstetrics and Gynaecology,

University of Pardubice, Pardubice, Czech Republic

R. Streda

Faculty of Health Studies, University of Pardubice,

Pardubice, Czech Republic observed one case of twins in 75 and 100 IU treatment group, as well (25\% risk).

Conclusions This study suggests that based on the dose which was chosen according to clomiphene citrate response, all treatment regimes were effective for ovulation induction. $50 \mathrm{IU}$ of follitropin beta daily is the appropriate starting dose to support ovulation for clomiphene citratesensitive women. The disadvantage may be an increased risk of cycle cancellation due to low ovarian response. Daily doses 75 or 100 IU of rFSH increase total consumption of gonadotropins.

Keywords Intrauterine insemination - Clomiphene citrate . Gonadotropins · Follitropin beta $\cdot$ Pregnancy rate .

Multiple pregnancy

\section{Introduction}

For unexplained infertility, mild male factor and anovulatory women who fail to ovulate or conceive with clomiphene citrate, gonadotropin ovulation induction combined with intrauterine insemination is used as the second-line therapy [8]. According to the available clinical studies about $15-20 \%$ of pregnancies are twins and $5 \%$ triplets or more $[8,17,25]$. Multiple pregnancies represent a relevant problem with high incidence of perinatal mortality and severe neonatal morbidity [23]. To prevent multiple pregnancies the goal of ovulation induction by gonadotropins is to achieve only mono-follicular development and ovulation [3, 20, 22]. Low-dose follicle stimulating hormone (FSH) regimens have succeeded in reducing the rate of multiple pregnancies to $2-6 \%$ and the rate of ovarian hyperstimulation syndrome (OHSS), as well [23]. 
The aim of ovarian stimulation is to reach, but not exceeding, the threshold level of FSH [14]. In case of inappropriate ovarian response it is necessary to adjust the dose of FSH. Hugues in Ref. [15] concluded that 'the choice of the FSH starting dose and the modality of subsequent dose adjustments are critical in controlling the risk of overstimulation'.

We hypothesized that starting dose 75 or $100 \mathrm{IU}$ of recombinant follicle stimulating hormone (rFSH) comparing with the starting dose $50 \mathrm{IU}$ of rFSH increases expected pregnancy rate due to achievement of higher number of follicles and reduction of the risk of cycle cancellation due to low ovarian response. On the other hand we expected mild increase multiple pregnancy rate and the risk of cycle cancellation due to high response.

The objective of the study was to determine the effect of different follitropin beta dose (50, 75 and 100 IU daily) on follicular development, thickness of the endometrium at the time of human chorionic gonadotropin (hCG) administration, total consumption of gonadotropins per cycle, pregnancy rate, risk of multiple pregnancy and the risk of OHSS.

\section{Materials and methods}

Between March 2005 and June 2006 women with a history of infertility signed informed consent and were recruited for this prospective study. Inclusion criteria were as follows: infertility at least 1 year, patients at least 18 years of age but not $>38$ years, BMI between 18 and $30 \mathrm{~kg} / \mathrm{m}^{2}$, basal serum FSH and luteinizing hormone (LH) $\leq 10 \mathrm{IU} / 1$, normal uterine cavity, at least one patent Fallopian tube assessed by hysterosalpingography or laparoscopy with chromosalpingography, history of clomiphene citrate therapy and sperm count after swim-up $\geq 5$ million $/ \mathrm{ml}$.

Based on patients history of response for clomiphene citrate treatment we divided the patients into 50, 75 and $100 \mathrm{IU}$ follitropin beta group (the patients with proved response to clomiphene citrate one tablet daily were allocated into 50 IU follitropin beta group, the women with no response to clomiphene citrate one tablet daily but proved response to two tablets daily were enrolled into 75 IU follitropin beta group and finally the patients with proved response to clomiphene citrate three tablet daily were put into 100 IU follitropin beta group). We started administration of 50, 75 or 100 IU follitropin beta subcutaneously on day 3, patients underwent a transvaginal ultrasonography on day 9 (Toshiba Famio with a 7.5 $\mathrm{MHz}$ probe) and if necessary we adjusted the gonadotropin dose (if we observed follicles $\leq 12 \mathrm{~mm}$ in diameter than we increased the FSH dose by $25 \mathrm{IU})$. When at least one follicle achieved $18 \mathrm{~mm}$ in diameter and endometrium was at least $8 \mathrm{~mm}$ thick we administrated hCG 5,000 IU subcutaneously and after 36-38 h we performed intrauterine insemination with luteal phase support by micronised progesterone $200 \mathrm{mg}$ daily vaginally. To minimize the risk of a multiple pregnancy, hCG was withheld if more than four follicles $14 \mathrm{~mm}$ in diameter were seen. The couple was advised not to have unprotected intercourse.

Statistical analysis was performed by $\chi^{2}$ test and ANOVA (GraphPad Software). A value of $p<0.05$ was considered statistically significant.

\section{Results}

We evaluated a total number of 92 ovarian stimulations for couples with unexplained infertility, anovulatory disorder or mild male factor. We performed 87 intrauterine inseminations (95\% of cycles with ovulation induction).

Baseline and hormonal characteristics of patients are summarized in Table 1. No significant differences according to study groups were documented. We noted some differences (but not significant) in the frequency of patients with ovulatory disorders and mild male factor. Patients with ovulatory disorders were more frequent in the $100 \mathrm{IU}$ group and patients with mild male factor in the 50 and $75 \mathrm{IU}$ groups. Cycle characteristics according to treatment group are described in Table 2. No significant differences were observed in the need to adjust the initial gonadotropin dose. Total consumption of rFSH was significantly higher in women receiving starting dose 100 and 75 IU daily compared with starting dose 50 IU daily $(p<0.001)$. There was a slight, but not a significant, difference in number of follicles and thickness of

Table 1 Basic and hormonal characteristics of patients

\begin{tabular}{|c|c|c|c|c|}
\hline & $\begin{array}{l}50 \mathrm{IU} \\
(n=35)\end{array}$ & $\begin{array}{l}75 \mathrm{IU} \\
(n=42)\end{array}$ & $\begin{array}{l}100 \mathrm{IU} \\
(n=14)\end{array}$ & $p$ value \\
\hline Age (years) ${ }^{\mathrm{a}}$ & $30 \pm 3$ & $30 \pm 3$ & $29 \pm 4$ & ns \\
\hline $\begin{array}{l}\text { Primary infertility } \\
(\%)^{\mathrm{b}}\end{array}$ & $25(71)$ & $27(65)$ & $8(58)$ & ns \\
\hline $\begin{array}{l}\text { Duration of infertility } \\
{\text { (years) })^{\mathrm{a}}}^{\text {(year }}\end{array}$ & $1.5 \pm 0.7$ & $1.4 \pm 0.7$ & $1.9 \pm 1.1$ & ns \\
\hline Cause of infertility ${ }^{b}$ & & & & ns \\
\hline Unexplained (\%) & $1(3)$ & $1(2)$ & $0(0)$ & \\
\hline $\begin{array}{l}\text { Ovulatory } \\
\text { disorder (\%) }\end{array}$ & $13(35)$ & $12(28)$ & $8(57)$ & \\
\hline Mild male factor $(\%)$ & $21(60)$ & $29(69)$ & $5(36)$ & \\
\hline Endometriosis (\%) & $0(0)$ & $0(0)$ & $1(7)$ & \\
\hline $\mathrm{FSH}(\mathrm{IU})^{\mathrm{a}}$ & $6.8 \pm 1.5$ & $6.6 \pm 1.5$ & $6.8 \pm 1.2$ & ns \\
\hline $\mathrm{LH}(\mathrm{IU})^{\mathrm{a}}$ & $5.6 \pm 2.0$ & $5.7 \pm 2.4$ & $7.1 \pm 2.3$ & ns \\
\hline
\end{tabular}

\footnotetext{
a Values are expressed as mean $\pm \mathrm{SD}$, ANOVA

b The frequency distribution analysis $\chi^{2}$ test
} 
Table 2 Characteristics of the stimulation cycles

\begin{tabular}{|c|c|c|c|c|}
\hline & $\begin{array}{l}50 \mathrm{IU} \\
(n=35)\end{array}$ & $\begin{array}{l}75 \mathrm{IU} \\
(n=42)\end{array}$ & $\begin{array}{l}100 \mathrm{IU} \\
(n=14)\end{array}$ & $p$ value \\
\hline $\begin{array}{l}\text { Initial dose } \\
\text { adjustment } \\
n(\%)^{\mathrm{a}}\end{array}$ & $5(14)$ & $2(5)$ & $2(14)$ & $\mathrm{ns}$ \\
\hline $\begin{array}{l}\text { Mono-follicular } \\
\text { cycle rate } \\
n(\%)^{\mathrm{a}}\end{array}$ & $10(29)$ & $13(31)$ & $4(28)$ & ns \\
\hline $\begin{array}{l}\text { Number of } \\
\text { follicles more } \\
\text { than } 16 \mathrm{~mm}^{\mathrm{b}}\end{array}$ & $2.0 \pm 0.8$ & $2.2 \pm 1.1$ & $2.5 \pm 1.8$ & ns \\
\hline $\begin{array}{l}\text { Thickness of } \\
\text { endometrium } \\
(\mathrm{mm})^{\mathrm{b}}\end{array}$ & $8.5 \pm 0.9$ & $8.7 \pm 1.4$ & $9.1 \pm 1.8$ & ns \\
\hline $\begin{array}{l}\text { Total } \\
\text { consumption } \\
\text { of rFSH (IU) }\end{array}$ & $483 \pm 192$ & $600 \pm 151$ & $830 \pm 268$ & $p<0.001$ \\
\hline $\begin{array}{l}\text { Duration of } \\
\text { cycle (days) }\end{array}$ & $13.3 \pm 1.7$ & $13.2 \pm 1.7$ & $13.4 \pm 1.8$ & ns \\
\hline $\begin{array}{l}\text { Minimal total } \\
\text { dose (IU) }\end{array}$ & 300 & 375 & 500 & \\
\hline $\begin{array}{l}\text { Maximal total } \\
\text { dose (IU) }\end{array}$ & 1,100 & 1,050 & 1,350 & \\
\hline
\end{tabular}

endometrium between groups. Duration of treatment does not differ in the study groups. Five cycles were cancelled $(8 \%)$. Reasons for cycle cancellation are presented in Table 3. Table 4 shows outcome of treatment. Clinical pregnancy rate per completed cycle was 22,10 and $28 \%$, respectively. No significant differences according to study group were documented. Total clinical pregnancy rate was $17 \%$ (15 pregnancies in 87 completed cycles). Spontaneous abortion occurs in one case. We observed one case of twins in 75 and 100 IU treatment group, as well (25\% risk of multiple pregnancy). None of the patients developed ovarian hyperstimulation syndrome.

Table 3 Cancellation of the cycles

\begin{tabular}{lllll}
\hline & $\begin{array}{l}50 \mathrm{IU} \\
(n=35)\end{array}$ & $\begin{array}{l}75 \mathrm{IU} \\
(n=42)\end{array}$ & $\begin{array}{l}100 \mathrm{IU} \\
(n=14)\end{array}$ & $p$ value \\
\hline $\begin{array}{l}\text { Cancellation of the } \\
\text { cycles } n(\%)^{\mathrm{a}}\end{array}$ & $4(11)$ & $1(2)$ & 0 & $\mathrm{~ns}$ \\
$\begin{array}{l}\text { Reasons for the cycle cancellation: } \\
\text { Low ovarian response } \\
n(\%)^{\mathrm{a}}\end{array}$ & $3(8)$ & 0 & 0 & $\mathrm{~ns}$ \\
$\begin{array}{l}\text { More than } 4 \text { follicles } \\
14 \text { mm } n(\%)^{\mathrm{a}}\end{array}$ & 0 & $1(2)$ & 0 & $\mathrm{~ns}$ \\
$\begin{array}{l}\text { The follicle at side of } \\
\text { salpingectomy } n(\%)^{\mathrm{a}}\end{array}$ & $1(3)$ & 0 & 0 & $\mathrm{~ns}$ \\
\hline
\end{tabular}

${ }^{a}$ The frequency distribution analysis was performed by $\chi^{2}$ test
Table 4 Outcome of the treatment

\begin{tabular}{lllll}
\hline & $\begin{array}{l}50 \mathrm{IU} \\
(n=31)\end{array}$ & $\begin{array}{l}75 \mathrm{IU} \\
(n=42)\end{array}$ & $\begin{array}{l}100 \mathrm{IU} \\
(n=14)\end{array}$ & $p$ value \\
\hline $\begin{array}{c}\text { Clinical pregnancy } \\
\text { rate } n(\%)^{\mathrm{a}}\end{array}$ & $7(22)$ & $4(10)$ & $4(28)$ & $\mathrm{ns}$ \\
$\begin{array}{c}\text { Abortions } n(\%)^{\mathrm{a}} \\
\begin{array}{c}\text { Ongoing pregnancy } \\
\text { rate } n(\%)^{\mathrm{a}}\end{array}\end{array}$ & $1(3)$ & 0 & 0 & $\mathrm{~ns}$ \\
$\begin{array}{l}\text { Twins } n(\%)^{\mathrm{a}} \\
\text { a }\end{array}$ & 0 & $4(10)$ & $4(28)$ & $\mathrm{ns}$ \\
\hline
\end{tabular}

${ }^{a}$ The frequency distribution analysis was performed by $\chi^{2}$ test

\section{Discussion}

Intrauterine insemination is recommended as the first-line treatment for couples with unexplained infertility or male subfertility $[6,9,17,27]$. The expected pregnancy rate of intrauterine inseminations in natural cycles is about $6.3 \%$ [24]. Ovulation induction increases the number of available oocytes and pregnancy rate [24, 26, 27]. Costellos's metaanalysis of randomized controlled trials [7] and Arici's study [1] revealed increasing pregnancy rate with ovulation induction by clomiphene citrate than natural cycle combined with intrauterine insemination. Clomiphene citrate is recommended as the initial treatment for women with unexplained infertility, mild male subfertility and WHO group II anovulation [9, 20]. This treatment achieves ovulation in approximately $70 \%$ of patients and pregnancy within 6 months in $35 \%[11,18]$. Multifollicular growth explains high rate of multiple pregnancies after clomiphene citrate therapy $-20 \%$ risk of twins and about $5 \%$ risk of triplets [8].

Costellos's metaanalysis of randomized controlled trials [7] and Balash's study [2] confirm increasing pregnancy rate with ovulation induction by gonadotropins than clomiphene citrate combined with intrauterine insemination. Randomized controlled trial [5] demonstrated that ovulation occurred in $70 \%$ in the recombinant FSH group versus $66 \%$ in the urinary FSH group, total dose of gonadotropins was $750 \mathrm{IU}$ versus $1,035 \mathrm{IU}$ and duration of treatment (10 days vs. 13 days), respectively. Other studies [10, 12, 13] compared recombinant gonadotropins versus urinary ones for ovulation induction combined with intrauterine insemination. In randomized study [10] Demirol proved pregnancy rate $25.9 \%$ versus $13.8 \%$, respectively. The advantage of recombinant FSH is availability of small dose-50 IU daily_for self subcutaneous administration and safe profile of treatment. Based on studies [16, 22], which compared different gonadotropin preparations in intrauterine insemination, recombinant $\mathrm{FSHs}$ result in a better outcome for unexplained infertility than urinary gonadotropins. The daily doses of recombinant FSH from 50 to $100 \mathrm{IU}$ were used [16]. 
For unovulatory woman with PCO syndrome treated with a starting dose of $50 \mathrm{IU} \mathrm{rFSH}$ there is necessary to increase a dose after 7-14 days of drug administration unless follicles are less than $12 \mathrm{~mm}$ in diameter [19]. A study conducted by Leader [18] compared dose increment 25 IU versus 50 IU. Similar with our results the 25 -IU group had a higher incidence of mono-follicular growth $(41.3 \%$ vs. $21.8 \%)$, ovulation ( $81.3 \%$ vs. $60.3 \%)$, lower total cumulative gonadotropins dose (887 IU vs. 984 IU). A dose increment 50 IU increases risk of overresponse from 5 to $20 \%$. About $5 \%$ cycles are cancelled due to low ovarian response. Several randomized studies are available for unovulatory women with PCO syndrome, seeking the dose of gonadotropins. Both randomized studies $[15,18]$ conclude that a starting dose of 50 IU recombinant FSH is adequate. Current study with low dose step up protocol [3] demonstrated $90 \%$ ovulation rate, $15 \%$ pregnancy rate, one case of OHSS $(1.3 \%)$ and risk of multiple pregnancy $25 \%$.

For women treated for unexplained infertility or mild male factor who fail to ovulate or conceive with clomiphene citrate, non-randomized Calaf's study [4] suggested starting dose $50 \mathrm{IU}$ recombinant FSH daily. One retrospective study [21] compared 50 and 75 IU of recombinant FSH combined with intrauterine insemination for unexplained infertility and achieved pregnancy rate $10 \%$. The study concluded that minimal FSH stimulation (up to two follicles) combined with intrauterine insemination cycle may reduce the rates of twins and high-order multiple pregnancies without affecting overall pregnancy rates.

We can explain the fact that study [9] observed pregnancy rate $34.3 \%$ in the gonadotropin group compared clomiphene citrate group for unexplained and male subfertility. This pregnancy rate was higher than in our study. Women in our study were treated with clomiphene citrate for 3 months before study occurred with additional pregnancy rate $12 \%$ [24]. Our pregnancy rate was higher (17\% vs. $12 \%$ ) and risk of cycle cancellation due to low ovarian response lower (8\% vs. $13.2 \%$ ) compared with another study [8].

The limitation of our study should be number of cases in groups. Despite this fact we proved significant differences in total consumption of gonadotropins between groups. Moreover, we intentionally did not compare other available prognostic markers (for e.g. FSH level, anti-Mullerian hormone (AMH), inhibin B etc.) with results of our study. Another trial (probably multicenter) is necessary for comparing all parameters in the future.

In summary, our work aims to assess the lowest effective gonadotropin dose and to find simple and easy to measure prognostic value for later response to ovarian stimulation combined with intrauterine insemination. We hope that results of our study may be helpful in tailoring treatment to individual patients.

\section{Conclusions}

This study suggests that based on the dose which was chosen according to clomiphene citrate response, all treatment regimes were effective for ovulation induction combined with intrauterine insemination. 50 IU of follitropin beta daily is the appropriate starting dose to support ovulation for clomiphene citrate sensitive women. The disadvantage may be an increased risk of cycle cancellation due to low ovarian response. Daily doses 75 or 100 IU of rFSH increase total consumption of gonadotropins. The choice of correct gonadotropin starting dose and its adjustment are important steps to minimize the risk of multi-follicular development, multiple pregnancy and OHSS.

Conflict of interest There are no conflicts of interests for this manuscript.

Open Access This article is distributed under the terms of the Creative Commons Attribution License which permits any use, distribution, and reproduction in any medium, provided the original author(s) and the source are credited.

\section{References}

1. Arici A, Byrd W, Bradshaw K, Kutteh WH, Marshburn P, Carr BR (1994) Evaluation of clomiphene citrate and human chorionic gonadotropin treatment: a prospective, randomized, crossover study during intrauterine insemination cycles. Fertil Steril 61: 314-318

2. Balasch J, Ballesca JL, Pimentel C, Creus M, Fabregues F, Vanrell JA (1994) Late low-dose pure follicle stimulating hormone for ovarian stimulation in intra-uterine insemination cycles. Hum Reprod 9:1863-1866

3. Balen A, Platteau P, Andersen AN, Devroey P, Helmgaard L, Arce JC (2007) Highly purified FSH is as efficacious as recombinant FSH for ovulation induction in women with WHO Group II anovulatory infertility: a randomized controlled non-inferiority trial. Hum Reprod 22:1816-1823

4. Calaf AJ, Ruiz Balda JA, Romeu SA et al (2003) Ovulation induction with a starting dose of $50 \mathrm{IU}$ of recombinant follicle stimulating hormone in WHO group II anovulatory women: the IO-50 study, a prospective, observational, multicentre, open trial. BJOG 110:1072-1077

5. Coelingh Bennink HJ, Fauser BC, Out HJ (1998) Recombinant follicle-stimulating hormone (FSH; Puregon) is more efficient than urinary FSH (Metrodin) in women with clomiphene citrateresistant, normogonadotropic, chronic anovulation: a prospective, multicenter, assessor-blind, randomized, clinical trial. European Puregon Collaborative Anovulation Study Group. Fertil Steril 69:19-25

6. Cohlen BJ, Vandekerckhove P, te Velde ER, Habbema JD (2000) Timed intercourse versus intra-uterine insemination with or without ovarian hyperstimulation for subfertility in men. Cochrane Database Syst Rev 2:CD000360

7. Costello MF (2004) Systematic review of the treatment of ovulatory infertility with clomiphene citrate and intrauterine insemination. Aust N Z J Obstet Gynaecol 44:93-102 
8. Crosignani PG, Somigliana E (2007) Effect of GnRH antagonists in FSH mildly stimulated intrauterine insemination cycles: a multicentre randomized trial. Hum Reprod 22:500-505

9. Dankert T, Kremer JA, Cohlen BJ et al (2007) A randomized clinical trial of clomiphene citrate versus low dose recombinant FSH for ovarian hyperstimulation in intrauterine insemination cycles for unexplained and male subfertility. Hum Reprod 22:792-797

10. Demirol A, Gurgan T (2007) Comparison of different gonadotrophin preparations in intrauterine insemination cycles for the treatment of unexplained infertility: a prospective, randomized study. Hum Reprod 22:97-100

11. Dickey RP, Taylor SN, Lu PY, Sartor BM, Pyrzak R (2004) Clomiphene citrate intrauterine insemination (IUI) before gonadotropin IUI affects the pregnancy rate and the rate of high-order multiple pregnancies. Fertil Steril 81:545-550

12. Gerli S, Casini ML, Unfer V, Costabile L, Bini V, Di Renzo GC (2004) Recombinant versus urinary follicle-stimulating hormone in intrauterine insemination cycles: a prospective, randomized analysis of cost effectiveness. Fertil Steril 82:573-578

13. Gerli S, Casini ML, Unfer V, Costabile L, Mignosa M, Di Renzo GC (2004) Ovulation induction with urinary FSH or recombinant FSH in polycystic ovary syndrome patients: a prospective randomized analysis of cost-effectiveness. Reprod Biomed Online 9:494-499

14. Homburg R, Howles CM (1999) Low-dose FSH therapy for anovulatory infertility associated with polycystic ovary syndrome: rationale, results, reflections and refinements. Hum Reprod Update 5:493-499

15. Hugues JN, Cedrin-Durnerin I, Howles CM et al (2006) The use of a decremental dose regimen in patients treated with a chronic low-dose step-up protocol for WHO Group II anovulation: a prospective randomized multicentre study. Hum Reprod 21:2817-2822

16. Isaza V, Requena A, Garcia-Velasco JA, Remohi J, Pellicer A, Simon C (2003) Recombinant vs. urinary follicle-stimulating hormone in couples undergoing intrauterine insemination. A randomized study. J Reprod Med 48:112-118

17. Khalil MR, Rasmussen PE, Erb K, Laursen SB, Rex S, Westergaard LG (2001) Homologous intrauterine insemination. An evaluation of prognostic factors based on a review of 2473 cycles. Acta Obstet Gynecol Scand 80:74-81
18. Leader A (2006) Improved monofollicular ovulation in anovulatory or oligo-ovulatory women after a low-dose step-up protocol with weekly increments of 25 international units of folliclestimulating hormone. Fertil Steril 85:1766-1773

19. Lopez E, Gunby J, Daya S, Parrilla JJ, Abad L, Balasch J (2004) Ovulation induction in women with polycystic ovary syndrome: randomized trial of clomiphene citrate versus low-dose recombinant FSH as first line therapy. Reprod Biomed Online 9:382-390

20. Messinis IE (2005) Ovulation induction: a mini review. Hum Reprod 20:2688-2697

21. Papageorgiou TC, Guibert J, Savale M et al (2004) Low dose recombinant FSH treatment may reduce multiple gestations caused by controlled ovarian hyperstimulation and intrauterine insemination. BJOG 111:1277-1282

22. Platteau P, Andersen AN, Balen A et al (2006) Similar ovulation rates, but different follicular development with highly purified menotrophin compared with recombinant FSH in WHO Group II anovulatory infertility: a randomized controlled study. Hum Reprod 21:1798-1804

23. Ragni G, Caliari I, Nicolosi AE, Arnoldi M, Somigliana E, Crosignani PG (2006) Preventing high-order multiple pregnancies during controlled ovarian hyperstimulation and intrauterine insemination: 3 years' experience using low-dose recombinant follicle-stimulating hormone and gonadotropin-releasing hormone antagonists. Fertil Steril 85:619-624

24. Streda R, Stepan J, Zadrobilkova I, Cermakova E (2007) Ovulation induction increases pregnancy rate during intrauterine insemination compared with natural cycles. Ceska Gynekol 72:397-402

25. Tur R, Barri PN, Coroleu B, Buxaderas R, Martinez F, Balasch J (2001) Risk factors for high-order multiple implantation after ovarian stimulation with gonadotrophins: evidence from a large series of 1878 consecutive pregnancies in a single centre. Hum Reprod 16:2124-2129

26. van Rumste MM, Custers IM, van der Veen F, van Wely M, Evers JL, Mol BW (2008) The influence of the number of follicles on pregnancy rates in intrauterine insemination with ovarian stimulation: a meta-analysis. Hum Reprod Update 14:563-570

27. Verhulst SM, Cohlen BJ, Hughes E, Te VE, Heineman MJ (2006) Intra-uterine insemination for unexplained subfertility. Cochrane Database Syst Rev 4:CD001838 